\title{
Resonancias de un pasado subterráneo: memorias de los paisajes sonoros de una escena rock underground del Sur de Brasil
}

\author{
Daniel Ribeiro Medeiros - Universidad Federal de Pelotas ${ }^{1}$ \\ Isabel Porto Nogueira - Universidad Federal de Pelotas ${ }^{2}$
}

DOI: http://dx.doi.org/10.5565/rev/periferia.511

\section{Resumen}

Este artículo trata de la categoría memorial (memoria de los paisajes sonoros de la escena rock underground) en los años noventa de una ciudad al Sur de Brasil. A partir de imágenes-recuerdos traídos por los colaboradores-memorialistas, se (re)construye tanto el campo sonoro pretérito como los sentidos memoriales que de ahí emergen. Primeramente, presentaremos los aspectos metodológicos y sus relaciones con el grupo de colaboradores así como los principales marcos teóricos que apoyan nuestro estudio en su totalidad. Después, construiremos nuestra categoría teórica dialogándola posteriormente con los datos empíricos. Concluimos que dicha categoría no solamente corresponde a las descripciones y significados de la cultura sonora pasada en sí mismos, sino que también implica en un contrapunto al que llamamos alteridad temporal.

Palabras clave: Memoria, identidad, paisajes sonoros, underground, escenas.

\begin{abstract}
This paper deals with the memorial category (soundscape's memories of the rock underground scene from 1990s) of one southern brazilian city. From the imagessouvenirs brought by our collaborators, it deals with the (re)construction of the past sonorous field as well as its memorial meanings. Firstly, we'll bring methodological aspects and their relations with the group of collaborators, as well as the theoretical frames that sustain our study at all. After, we'll construct theoretically our category, relating it with the empirical data. We conclude that these memories respond not only to the descriptions and meanings related exclusively with the past sound culture but too with how the memory of the sounds plays a role in a temporal otherness.
\end{abstract}

Keywords:Memory, identity, soundscapes, underground, scene.

\footnotetext{
${ }^{1}$ Enviar correspondencia a: Daniel Ribeiro Medeiros (danielribeiromedeiros@gmail.com)

${ }^{2}$ Enviar correspondencia a: Isabel Porto Nogueira (isabel.isabelnogueira@gmail.com)
} 
Autor/es, título, perifèria $x(y)$, mes 2016

revistes.uab.cat/periferia

\section{Introducción}

Este artículo plantea uno de los aspectos que han emergido en el proyecto de tesis Rock pelotense en los años 1990: escena, memoria e identidades de una práctica roquera en el extremo Sur de Brasil ${ }^{3}$, cuya investigación corresponde al cómo se (re)construye una memoria socio-musical de la escena (Straw, 2004; Bennett, 2004 ; 2013) rock undergroundde la ciudad de Pelotas ${ }^{4}$ en los años noventa. En dicho trabajo, nos hemos encontrado con un contexto de investigación en el que no había estudios ni registros substanciales que aportaran datos significativos tanto de dicha escena como de las prácticas socio-musicales ${ }^{5}$ de los músicos relacionados con ella. De ese modo, nos hemos apoyado primeramente, en la perspectiva metodológica de la historia oral, a través de la cual hemos constituido un conjunto de fuentes orales a partir de "[...] entrevistas grabadas con actores y testigos del pasado [...]" (Alberti, 2000). A partir de ahí, emergió un amplio conjunto de narrativas en las quelos relatos retrospectivos tuvieron en cuenta un conjunto de aspectos relacionados con sus experiencias socio-musicales pretéritas. Dichos relatos se caracterizaron en cuanto autobiografías musicales: trayectorias (re)construidas a través de la reconstitución de "[...] relaciones sociales experimentadas [...]" en el pasado a lo largo de sus recorridos musicales (Gomes, 2012). Además, aunque dichas autobiografías musicales hayan sido construidas a través de perspectivas individuales,abrieron puertas de acceso al contexto y cultura del pasado (Alberti, 2000).

\footnotetext{
${ }^{3}$ Este proyecto se realiza desde el año 2013 dentro del Programa de Posgrado en Memoria Social y Patrimonio Cultural (PPGMP) de la Universidad Federal de Pelotas (UFPel - Brasil).

${ }^{4}$ Esta ciudad está ubicada en el extremo Sur de la provincia de Rio Grande del Sur (Brasil).

5 "[...] El término 'práctica musical' abarca actores sociales, las músicas que ellos producen y/o consumen, las representaciones sociales que les dan sentido y las acciones musicales de ejecutar, improvisar, componer y oír, entre otras. Por tanto, es 'práctica significativa': no solo '[...] comunica o expresa significados pre-existentes sino también 'posiciona sujetos' en un proceso de semiosis' [...]" (Arroyo, 2010, p. 25).
} 
Autor/es, título, perifèria $x(y)$, mes 2016

revistes.uab.cat/periferia

A partir de ese contexto empírico y metodológico, fueron realizadas más de treinta entrevistas individuales entre los años de 2013-2014con colaboradores ${ }^{6}$ que actuaron en la escena rock undergroundpelotense de los años 90s. Hemos llegado a ellos por el simple hecho de que el propio investigador también participó (tocando en un grupo de heavy metal) en dicha escena, habiendo tenido contacto con muchos de los colaboradores en el pasado. Además, muchos de los entrevistados apuntaron a otros posibles colaboradores a lo largo de las entrevistas, teniendo en cuenta los aportes que podrían traer. Muchos de los apuntados ya habían sido entrevistados, lo que legitimó las elecciones hechas de antemano por el propio investigador.

Además, es importante señalar que uno de los retos de la investigación ha sido el hecho de que el grupo social pasado ya no existe. En la medida en que se han trasladado de un contexto temporal de vida en el que eran músicos adolescentes, con sus preocupaciones correspondientes, a otro en el hoy, en que muchos asumen papeles de padres, madres, profesionales, etc, se trata de un grupo que se ha fragmentado a lo largo del paso del tiempo. No existiendo más el grupo social del pasado, se constituyó un contexto de investigación en que no haytampoco la articulación de una memoria colectiva (Halbwachs, 1990) de dicha escena. O sea:un conjunto de personas que plantea y organiza su relación con el pasado a través de rituales, discursos, etc, colectivamente articulados y compartidos en el presente como forma de representación de su propia identidad en cuanto grupo.Por lo tanto, nos encontramos con el siguiente problema: ¿Cómo podríamos llegar a una (re)construcción de ese pasado en el que se dibujara un cuadro general de un colectivo socio-musical pretérito?. Nuestra hipótesis fue que a través del enfoque hacia las prácticas socio-musicales (aunque tomadas a partir de perspectivas individuales), pudiéramos tener un eje significativo en el que los colaboradores pudieran (re)construir sus pasados socio-musicales y tejer las bases sociales tanto de sus recorridos personales como del espacio socio-musical escena.

\footnotetext{
6 Todos/as los/as colaboradores/as han tocado en grupos de rock en esa época,a excepción de solamente uno de los entrevistados que actuó como colaborador en la escena.
} 
Autor/es, título, perifèria $x(y)$, mes 2016

revistes.uab.cat/periferia

A lo largo de las (re)construcciones fueron emergiendo una serie de temáticas que, a partir de la perspectiva ético-émica ${ }^{7}$, ayudaron a tejer una cantidad de categorías memoriales que, de una forma u otra, reflejaron un enlazamiento entre memoria, identidad y prácticas socio-musicales. De ese modo, entramos en el campo de la antropología de la memoria (Candau, 2005; 2011), en la que se busca comprender cómo los sujetos comparten "[...] prácticas, representaciones, creencias, recuerdos [...]" (Candau, 2011, p. 11).Entendemos que tales categorías componen una textura memorial que al fin y al cabo, conforma una cultura de rememoración que entrelaza la (re)construcción-representación-significación del pasado en el presente (Halbwachs, 2004 [1925]; 1990; Candau, 2005; 2011; Misztal, 2003; Pollak, 1992; Jedlowski, 2001) a través de lo que llamamos memorias socio-musicales.

A través de los análisis de las entrevistas realizadas, emergieron una cantidad de categorías memoriales entre las cuales el sonido no es menos importante. Hemos visto que las performances memorialesacerca de las (re)construcciones de los sonidos pasados, están relacionadas con una serie de otros aspectos socioculturales. $O$ sea: el sonido no viene separado de las condiciones materiales y contextos de su producción.Por lo tanto, es de esa manera que se componen lo que llamamos memorias de los paisajes sonoros de la ERUP9O ${ }^{8}$.

Hemos apoyado la comprensión-interpretación de esta y todas las demás categorías en nuestro estudio por medio de la perspectiva de la descripción densa de CliffordGeertz (2008). La comprensión fue - y está siendo - emprendida a través de un "[...]esfuerzo intelectual $[\ldots]$ " que desde los aspectos descriptivos a los sentidos socio-culturales, interpretamos las "[...] estructuras significantes $[\ldots]$ "que constituyen las "[...] telas de significados $[\ldots]$ " que los propios sujetos construyen y a las cuales se amarran (Geertz, 2008, p. 4-5).

\footnotetext{
7 Esa perspectiva corresponde a lo que Portelli (2010) llama autoridad compartida: ambos investigadores y colaboradores, aportan en la construcción del conocimiento desde el área de la historia oral.

8 A partir de ahora llamaremos la EscenaRock UndergroundPelotensede los años noventa a través de este acrónimo.
} 
Autor/es, título, perifèria $x(y)$, mes 2016

revistes.uab.cat/periferia

Para presentar las memorias de los paisajes sonoros de la ERUP90, en primer lugar, construiremos las bases teóricas de dicha categoría memorial. En segundo lugar, analizaremos pasajes de las narrativas, mostrando sus bases empíricas. En las consideraciones finales, presentaremos un resumen analítico en el que serán relacionados los aspectos generales que presentaremos a lo largo del artículo, y relacionaremos algunos puntos de la temática de los paisajes sonoros con la textura memorial general en nuestro estudio.

\section{Memorias de los paisajes sonoros: bases teóricas de una categoría memorial}

Reflexionando acerca del paisaje acústico, Murray Schafer enfoca el estudio de las sonoridades de los medios en los cuales vivimos: los paisajes sonoros. Su estudio envuelve la comprensión de las características que componen los más variados ambientes acústicos (Schafer, 2011). Aunque pueden ser naturales o culturales (Pinto, 2001), nos interesa la segunda perspectiva, pues los variados contextos urbanos presentan "[...] rasgos sonoros característicos $[\ldots]$ ", lo que nos pone en una perspectiva en la que debemos mirarlos de una manera no indiferente a los medios socio-culturales de los cuales resuenan. Además, denotando identidades sonoras, pueden cumplir una función de memoria colectivo-social (Atienza, 2007).

Por otro lado, Woodside (2008) Ilama la atención sobre la perspectiva histórica de los paisajes sonoros. Según el autor, son espacios en los que los sonidos interactúan intencional o accidentalmente, poseyendo lógicas interiores típicas y correspondientes a los referentes de los entornos socio-culturales de donde emergen. De esa forma, indican las condiciones de su producción así como del desarrollo de una sociedad. Poseen "[...] historicidad y van de manos con el devenir de una sociedad $[\ldots] "$ " (Woodside, 2008, p. 3). Por tanto, en la medida en que las experiencias de los sujetos son intercedidas por los sonidos, emerge la posibilidad de memorias del sonoro, pues:

[...] Aunque el paisaje sonoro se construya a partir de lo que ocurre en un entorno, éste también impacta en los oídos, emociones y recuerdos de la gente a lo largo de su vida como individuos y les permite mantener un nexo con su comunidad ya sea de forma generacional y/o cultural [...] (Woodside, 
Autor/es, título, perifèria $x(y)$, mes 2016

revistes.uab.cat/periferia

2008, p. 4).

Por eso, entendemos que las imágenes-recuerdos de los colaboradores reflejan índices-representaciones de las marcas sonoras que han sido experimentadas en un pasado común, lo que posibilita la emergencia deun "[...] macro-discurso [del] sonoro que [re]construye parte de la identidad de una comunidad $[\ldots]$ " (Woodside, 2008, p. 4).

Por otro lado, si música-sonidos y los contextos dicen mucho acerca de la construcción de las experiencias en el mundo socio-cultural donde los sujetos se construyen a sí mismos, luego, las memorias de los paisajes sonoros corresponden a lo que DeNora (2007) entiende de la música en cuanto tecnología del self: es un importante instrumento en la (re)construcción de la memoria e identidad una vez que está presente en varias de nuestras experiencias en el mundo. O sea, la música, los sonidos, los ambientes acústicos en el devenir, hacen parte del "[...] ambiente material y estético $[\ldots] "$, ayudando a conformar las concepciones, recuerdos, etc, de la gente acerca del pasado, presente y futuro. En la medida en que la música y el sonoro están asociados a experiencias relacionadas con el pasado, y siendo este mismo pasado un "[...] artefacto de la memoria y su [re]constitución [...]" (DeNora, 2000, p. 66-67), la categoría memoria de los paisajes sonoros emerge como elemento potencial en el trabajo de memoria. Por tanto memoria, identidad y paisajes sonoros se entrelazan.

En la temática de nuestro estudio, cada colaborador actuó como un testigo auditivo (Schafer, 2011) delcampo sonoroexperimentado, una vez que sus remembranzasreflexiones se refieren alas"[...] prácticas sonoras pretéritas $[. . .]^{\prime \prime}$. Estos sonidos de la memoria se presentan como relatos de experiencias sonoras que se constituyencomo meta-comentarios que revelan "[...]un tipo de percepción y [re]construcción de la vida sonora de un lugar o [...] de un individuo, sus relaciones y vivencias en un espacio [y tiempo] determinado[s] [...]". En ese narrar, se desarrolla una "[...] interpretación de una realidad sonora pasada [...]" (Silva, 2014 , p. 114,123) que debe tener en cuenta que (1) estos recuerdos remiten a representaciones de los rasgos sonoros pasados a partir de un "[...] oír algo no simplemente presente al oído $[\ldots]^{\prime \prime}$. O sea: es el sonoro representado en el 
Autor/es, título, perifèria $x(y)$, mes 2016

revistes.uab.cat/periferia

presente; (2) en la medida en que es algo representado, los significados del sonoro se constituyen a través de experiencias adjetivas (Frith, 1998, p. 249,263).

Por tanto, a través de las imágenes-recuerdospresentadaspor los colaboradores, entendemos que la categoría ético-émicamemorias de los paisajes de la ERUP90,emerge como clave teórica-empírica que nos permite un dibujo del ambiente sonoro y del entorno material de donde provenían los sonidos (perspectiva descriptiva), así como de los sentidos memoriales (significación) correspondientes.

\section{Memorias de los paisajes sonoros: ruidos de una escena subterránea}

Las memorias de los colaboradores-memorialistas tejieron una serie de imágenesrecuerdos acerca de los rasgos sonoros del paisaje acústico pretérito de la ERUP90a través de dos subtemáticas principales. La primera tiene que ver con un rellenarsonorizar espacios-equipamientos urbanos con los sonidos del rock: práctica sociomusical enlazada a la vida nocturna (generalmente a los fines de semana) en la que el hecho de acudir a bares y traileres $^{9}$ estaba asociado al entrelazamiento de actividades sociales como beber, conversar, conocer personas, encontrar los amigos, etc con el componer sonoramente - a través del rock - tales espacios. No se trata de recuerdos correspondientes a la calidad de estos ambientes sonoros, sino de la conformación de territorios sonoros nocturnos de encuentro entre aquellos/as identificados/as con la cultura del rock.

Los recuerdos acerca del llevar cintas casete a bares y traileres y solicitar a los dueños de dichos equipamientos para que se las tocaran en los equipos de sonido, nos conducen directamente al concepto de musicking ${ }^{10}$ (Small, 1998), en la medida en que la música corresponde a un conjunto de performances-actividades

\footnotetext{
${ }^{9}$ Se trata de un término en portugués que, así como el tráiler en castellano, se refiere al remolque que se engancha a un vehículo tractor. Al contrario del sentido en castellano, enel que el vehículo tractor se refiere a los camiones, los traileres, por lo menos en el Sur de la provincia de Rio Grande del Sur donde se encuentra la ciudad de Pelotas, se refieren a las caravanas que, originariamente elaboradas para viajes, eran preparadas para la venta de comidas y bebidas. En esa época, en la ciudad de Pelotas, había muchas de esas caravanas aparcadas en las calles, a las que la gente iba a comer, charlar y beber.
}

${ }^{10}$ Traducimos este término como musicar, igual que en lengua portuguesa. 
Autor/es, título, perifèria $x(y)$, mes 2016

revistes.uab.cat/periferia

concernientes directa o indirectamente a actos musicales. Una vez que el sustantivo "música" se transforma en verbo, denotando acción ${ }^{11}$, el "[...] musicar es participar, en cualquier capacidad, en una performance musical $[\ldots]$ ", esté dicha performance relacionada con la ejecución de algún instrumento, con la escucha de alguna música, con los ensayos o con el hecho de bailar. El musicar también es extensivo a las actividades de aquellos que compran billetes en las puertas de salas de concierto o también a los que arreglan los escenarios para que se den tales eventos. O sea, el llevar cintas casetepara que se sonorizaran los ambientes sociales correspondientes,puede ser visto como unaacción delmusicar. De esa forma, la naturaleza y los significados de la música, están en los propios actos musicales de la gente (Small, 1998).

Además, dichos recuerdos remiten a los propios sentidos del frecuentar lugares pasados memorables. Son espacios en el mismo sentido de los pedazos de Magnani $(2002)^{12}$ : memorables en la medida que corresponden a sitios donde se permitía la constitución de un paisaje sonoro adecuado, un territorio en el que el sonido se corresponde directamente con las distorsiones de las guitarras eléctricas, las batidas fuertes de las baterías, los gritos de los cantantes, así como con las sociabilidades de aquellos identificados con el rock en la ERUP9O.

Tras una serie de recuerdos sobre los tipos sociales y el entorno del estadio del EsporteClube $^{13}$ Pelotas, elcolaborador E.A. al ser preguntado respecto de lo que se

\footnotetext{
${ }^{11}$ De "music" a "musiking". O sea, de "música" a "musicar".

12 El pedazo se caracteriza como un punto de referencia para un determinado grupo de personas: "[...] El término [pedazo], en realidad, designa aquel espacio intermedio entre lo privado (la casa) y lo público, donde se desarrolla una sociabilidad básica más amplia que aquella fundada en los lazos familiares pero más densa, significativa y estable que las relaciones formales e individualizadas impuestas por la sociedad [...]. Se constituye a partir de la interdependencia entre una dimensión espacial, territorial y social, en que "[...] el pedazo es el lugar de los colegas, de los allegados. Aquí no es necesaria ninguna interpelación: todos saben quiénes son, de dónde vienen, lo que les gusta y lo que se puede o no hacer [...]" (Magnani, 2002, p. 21).
}

${ }^{13} \mathrm{Club}$ donde los asociados practican deportes. 
Autor/es, título, perifèria $x(y)$, mes 2016

revistes.uab.cat/periferia

hacía en los lugares por él recordados, remite al trailer llamado Carranca ${ }^{14}$ y al bar Pássaro Azul ${ }^{15}$ (dos pedazos de la escena pasada). Recordando la práctica de llevar cintas casete como un rasgo decisivo al frecuentar dichos establecimientos, señala:

[...] [Entrevistador: ¿Qué es lo que se hacía en estos lugares?] Bueno, [...] una de las cosas interesantes sobre el Carranca y sobre el Pájaro Azul y eso es un rasgo común y decisivo sobre estos dos lugares, es lo siguiente: eran lugares en los que podías [...] sacar una cinta casete de tu bolsillo, pedir al tío [el dueño del bar] para que se la pusiera [en el equipo de sonido] y él ponía la música que tú querías. Ellos ponían rock. Entonces eso era decisivo sobre los dos lugares. Ellos ponían rock. Y ponían lo que pidieras [...] Si tú llevaras una cinta caseteen el bolsillo, como era un hábito... de... mi generación, ¿vale?

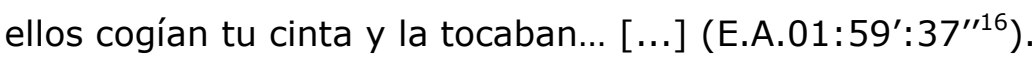

El colaborador A.L. también nos remite al musicar-sonorizar a través del hecho de llevar cintas casetecomo un factor determinante para la adopción de un equipamiento adecuado a los del rock (el bar Pájaro Azul):

[...] [Entrevistador: ¿Puedes hablarme un poco respecto... a los locales relacionados al rock en la ciudad de Pelotas: cuáles eran los lugares donde la gente se encontraba? ¿Qué se hacía en dichos lugares...?] iVale! Entonces... [...] cuando [...] empecé a salir a la noche, había el Pájaro Azul y el muro del [supermercado] Real. [...] había el Pájaro Azul a un lado de la calle y del otro lado de la Avenida había el muro del supermercado con... una cerca de espinos atrás del muro... y la gente se juntaba por allí... Toda la pandilla del rock, del metal, en los fines de semana, viernes por la noche, sábado por la noche... la gente se iba a ese bar: beber cerveza, conversar, $[\ldots]$, oír música... Se llevaba cinta caseteen el bolsillo y... y se la daba al dueño del bar para que

\footnotetext{
14 "Carranca" es un término brasileño que se refiere a un tipo de escultura producida en madera y que corresponde a imágenes de animales o humanos y que se popularizó a través del trabajo de miles de artesanos.

15 La traducción de "Pássaro Azul" al castellano sería "Pájaro azul".

${ }^{16}$ Minutaje de los pasajes de las entrevistas grabadas.
} 
Autor/es, título, perifèria $x(y)$, mes 2016

revistes.uab.cat/periferia

se la pusiera en el equipo [de sonido] y tal... [...] muchas personas llevaban sus cintas para que se las escucháramos allá y entonces... lo que se buscaba era eso: tener un bar para nosotros sentar, beber, conversar y oír música [rock]. Y el Pájaro Azul a lo largo de mucho tiempo fue ese espacio... [...] (A.L., $\left.1: 13^{\prime}: 27^{\prime \prime}\right)$.

Entre los recuerdos acerca de los lugares frecuentados por los del rock, el informante A.F.habla acerca de un bar ubicado en la playa de la ciudad en el que la gente también llevaba cintas casetepara que el propietario del establecimiento las pusiera en el equipo. Además, presenta algunos de los significados que para él tenía dicha actividad:

[...] en elLaranjal ${ }^{17}$, en una época, [...] pero [...] en la mitad de los años noventa, era un punto de encuentro... Había el... Ilamado bar doZóide... donde la gente llevaba cintas grabadas y el dueño del bar las ponía para tocar... Y aquello era algo... ila gente se volvía loca con aquello! [risas] Una cosa sencilla pero que hoy es ridículo... Pero era importante porque el... salir de casa, llevar una cinta y... el dueño del bar poner tu cinta... [risas]... [Entrevistador: Sí. Háblame un poco más sobre la importancia de eso... ¿Por qué crees que era algo tan importante...?] Porque era tan raro, tan difícil conseguir oír ese tipo de música en un lugar con otras personas... Oíamos en casa solos, con los amigos... Pero... en un sitio público tú no... [...]. Era la manera de conseguir expresarte como... fan de rock; como apreciador de rock [...]. Oír la música de la banda que te gusta... delante de otras personas... [...] eso es importante [...] para todos los que les gusta la música... Y... había algunos lugares en que eso ocurría... Había [...] un trailer también atrás del... estadio del Pelotas [club de futbol], que era el Carranca... ifamoso Carranca!

17 La playa del Laranjal (el nombre, en castellano, remite al mismo significado que en portugués: un terreno en el que hay una plantación de naranjos) está situada en la ciudad de Pelotas. La playa es bañada por el agua de la Laguna de los Patos, en la provincia de Rio Grande del Sur. Se trata de un barrio con muchas viviendas veraniegas, bares, restaurantes, etc. 
Autor/es, título, perifèria $x(y)$, mes 2016

revistes.uab.cat/periferia

Que también la gente llevaba las cintas; él [el dueño del trailer] las ponía; había hasta algunos conciertos de bandas a veces [...] (A.F.,01:48':00").

Por otro lado, emergieron también imágenes-recuerdos acerca de las cualidades de los rasgos sonoros, sobresaliendo las sonoridades que componían el espacio de los ensayos y festivales de la ERUP90. Remiten a memorias-ecos del campo sonoro característico que, en el propio trabajo de memoria de cada sujeto, se relacionan directamente conlos aspectos de las condiciones materiales de producción sonora disponibles en esa época. En este jugar entre el sonoro-condiciones de producción, se retroalimentan dos aspectos fundamentales en el entendimiento de un paisaje sonoro: el sonido y sus referentes materiales, sociales, culturales, etc. El colaborador A.L., por ejemplo, recordando sobre cuando empezó sus actividades con bandas de rock, (re)construye lo que entiende como contexto de dificultades materiales, mercadológicas y económicas. Estos elementos ayudan a componer parte de las consecuencias sonoras correspondientes, trayendo un significado memorial relacionado con la idea de que para que se pudiera tener una banda, se tendría que llevar dicha actividad en los términos de una expresión brasileña: no peito-e-na-raça ${ }^{18}$. Además, hace comparaciones entre el ayer-hoy:

[...] Empezamos [...] a intentar a montar una banda... con lo que se tenía: [...]iah!... guitarra vieja, podrida... En la época era difícil el acceso a instrumentos musicales. Era complicado. Era todo muy caro; no existían buenos instrumentos a la venta en la ciudad [...]. Me acuerdo de ir a ensayar... Yo tenía un bajo Jennifer ${ }^{19}$ que era muy malo... Pagabas caro por una cosa mala... No había instrumentos importados en la ciudad... Eran... todos eran malos... Yo tocaba con un bajo Jennifer, un amplificador Frahm ${ }^{20}$ horrible que no.... Ni existían amplificadores de bajo; no se conseguía... Tocaba con un bajo Jennifer, un amplificador Frahm e iba a ensayar con el amplificador Ilevándolo por debajo del brazo, [...] el bajo en la otra mano, cogía un autobús llevando

\footnotetext{
18 Es decir, llevar a cabo una actividad con muchas ganas pese a las dificultades.

19 Marca del instrumento.

20 Marca del producto.
} 
Autor/es, título, perifèria $x(y)$, mes 2016

revistes.uab.cat/periferia

todo aquello a mano, pasaba una trabajera para irme a ensayar... Y la batería tapaba todo... Encendías la guitarra, bajo, vocal y solo se oía la batería en el ensayo, porque los amplificadores eran todos malos [...]. Era terrible... hoy en día ves la facilidad que se tiene: un montón de estudios para ensayo; buenos equipos... Todo a la mano... [...]. Antiguamente no había nada de eso. Antiguamente era nopeito e na raça. Era complicado tener una banda porque... tenías que tener muchas ganas $[. .$.$] porque [. .$.$] la calidad de sonido$ era inexistente. Era todo muy malo... De repente eso haya influenciado la sonoridad de mucha gente porque en realidad no había cómo escoger un timbre... No había nada de eso... Hasta que conseguías un pedal $\operatorname{Boss}^{21}[\ldots]$ de distorsión en esa época... Pero... tener una guitarra buena, importada, era privilegio de pocos... [...] (A.L.00:13':46").

A través de los recuerdos de los ensayos de la banda en la que tocaba y en la medida en que necesitaban de una batería y un sitio para practicar, el informante G.T.habla acerca de la característica estético-sonora del ambiente socio-musical que compartía con otras bandas:

[...] No sé cuántas bandas tocaban allá... [...]. Me acuerdo de que ellos [las otras bandas] tocaban hardcore y a veces con unos teclados con distorsión; unas cosas extrañas así... [...]: cogían un tecladoCasio ${ }^{22}$, le ponían una distorsión [representa vocalmente los sonidos que le vienen en el recuerdo] y hacían un sonido muy feo así... Golpeaban aquellos platos [de batería]... [Entrevistador: ¿Qué es ese "podrão"23? ... ] [...] Era... no sé tío... Los tíos siempre borrachos también... Era una suciedad general [risas]... Como yo digo: el modo de vida de uno se refleja en el sonido. Si uno anda con la ropa toda sucia, con los pelos sucios, no se ducha, se emborracha todos los días,

\footnotetext{
${ }^{21}$ La marca del pedal de efectos.

${ }^{22}$ La marca del teclado.

${ }^{23}$ Se trata de un término, al menos local, que en el castellano se puede referir a "podrido". Pero en términos de una expresión émica, se refiere a sonidos considerados feos, ruidosos, raros. El entrevistado había mencionado dicho término momentos antes de lo que está en esta cita.
} 
Autor/es, título, perifèria $x(y)$, mes 2016

revistes.uab.cat/periferia

vomita y se despierta por encima del vómito, ese tipo de cosa podrida, eso aparece en el sonido. Cuando uno va a elegir el timbre [del instrumento], elige el timbre más cercano a aquel vómito que él... vivió allí... Entonces... la música de ellos era como un vómito. Y ellos querían que fuera así. Les gustaba esa estética fea... [...] iTalpodrêra iba lejos! Porque había unos tíos muy radicales. [...] había gente que era tan radical en esa cosa de 'ipodrêra!', 'ipodrêra!'... [...] Había unosque decían así: 'iAh! iEso ahí es cosa de falso!'. Todo era falso. [...] Y había unos radicales que solo querían 'iAhora solo voy a oír taladro, licuadora!'. Ellos se iban a ese lado y oían aquellos industriales [se refiere a un estilo musical] que yo ni sé muy bien qué es... Un metal industrial creo que sea... Es cosa con ruido de martillo neumático, sirena de fábrica, esas cosas muy urbanas y muy brutales así... Sonido irritante. [...] (G.T.00:31':19").

Igualmente, el mismo testimonio añade que la banda en la que tocaba también componía y compartía ese mismo paisaje sonoro podrêra en la medida en que estaban todos/asinmersos/as en un mismo contexto de condiciones de producción de sonido:

[...] desde allá quedó más claro para mí, que a muchas de esas bandas les gustaba vernos tocar porque [nuestro] sonido era podrido. Los equipos, aquello todo que teníamos a la mano, batería de... quinta categoría ${ }^{24}$, con los platos rotos $[. .$.$] ... Eso era algo que les agradaba. Entonces nosotros$ tocábamos [su banda] enel medio de un montón de punks. Tocábamos con aquel sonido sucio, y nuestras músicas tenían algunos pasajes que eran más pesados, más agresivos... A ellos les gustaba. Porque aquello tenía alguna relación con lo que ellos hacían también... Era diferente: había notas, había muchos más arreglos y cosas... Pero... había alguna relación. Y eso se me quedó un poco más claro en dos mil cuatro... cuando nosotros [su banda] nos presentamos en el Conservatorio de Música y M.S.[un amigo suyo] estaba en la platea y después se vino a mí y me comentó: '!Vaya! Estaba muy guay

${ }^{24}$ De pésima calidad. 
Autor/es, título, perifèria $x(y)$, mes 2016

revistes.uab.cat/periferia

vuestro concierto. Pero estaba muy limpio y está diferente el sonido. Ahora está muy bonito'. Y empecé a enterarme: claro, lo que él oía antes no era lo que queríamos [su banda] pasar, era lo que conseguíamos pasar [risas] con aquel equipo que se tenía en aquel tiempo. Y las grabaciones horrorosas de cinta casete... Era eso lo que él oía...... [Entrevistador: ¿Y eso tiene relación con el podrêra...? ¿Al sonido podrêra, la actitud podrêra...?] Sí, pero en nuestro caso [de su banda]... nos sometíamos a hacer un sonido podrido porque no se tenía otra opción. O se hacía aquel sonido podrido o no ${ }^{25}$. Por ejemplo: mi amplificador Brabus ${ }^{26}$, que compré por cincuenta reales... y que es una cajita de abejas de ese tamaño, pequeñito, no tenía volumen para tocar junto con una batería. Pero yo hacía tener volumen: yo cogía el pedal de distorsión, lo ponía en el máximo, articulaba todas las notas con el whawha, con el pie, y al final quedaba aquello: se parece a un pato vomitando [imita con la voz el efecto producido por el proceso descrito]. Y aquello era lo que los tíos oían. [...] (M.S.00:37':39"').

Por otro lado, son las memoriasde lospaisajes sonoros correspondientes a los festivales las que más emergieron. La forma de (re)construcción de esosrecuerdos es la misma que hemos visto más arriba: el sonoro directamente relacionado con la calidad de los equipos de música disponibles. El colaborador E.A. por ejemplo, trajo una imagen-representación general acerca de su experiencia en los festivales locales en esa época (con su banda) en la cual dibuja parte de los rasgos sonoros. Tras comentar que los festivales eran casi siempre realizados en bares, se le pregunta sobre los escenarios generales de estos eventos:

[Entrevistador: ... Si pudieras describirme el escenario... ¿Cómo eran estos escenarios?] Había solo un equipo de música para todas las bandas. Muchas veces el equipo no era suficiente. Entonces, me acuerdo de tocar en lugares en que... no se lograba oír lo que tocábamos. Todo era muy precario. Porque en esa época todavía no habían llegado los... iBueno! Hasta una determinada

\footnotetext{
${ }^{25}$ En el sentido de "o se hacía ese tipo de sonido" o "no se hacía música". Una cosa u otra. 26 Marca del producto.
} 
Autor/es, título, perifèria $x(y)$, mes 2016

revistes.uab.cat/periferia

época, $[\ldots]$, en el comienzo no, no habían llegado los $\operatorname{cubos}^{27}$ aquí. Aunque existían, eran muy caros. Entonces poquísima gente los tenía. Y la gente que los tenía no los dejaba circulando para que otros los usaran. Entonces se tocaba mucho con un amplificadorFrahm; todavía se veían algunos amplificadores GianniniTremendão ${ }^{28}$, aquellos a válvula [...] que en esa época funcionaban mal... muy mal... Era precario [...]. Me acuerdo de tocar en sitios en los que el bajo parecía que tenía distorsión. Porque no había ni un grave ${ }^{29}$ y solamente resultaba aquel sonido de distorsión. Me acuerdo de tocar en sitios así... [...] (E.A.02:15':40").

Recordando bandas y músicos que se habían presentado en el festival llamado Anarcofesta $^{30}$ a comienzos de los noventa, el informante J.G. (re)construye unaimagen del rasgo sonoro (ruidêra ${ }^{31}$ ) de tal evento a modo de representación del paisaje sonoro general de la escena pasada:

[Entrevistador: ¿Cómo era ese festival?... Si pudieras describírmelo...] iHombre! Era un festival muy parecido con los de hoy sino que era mucho más precario... Porque no había... Hoy en día la gente ya [...] tiene más acceso a equipos [...] Por ejemplo: en aquella época... aquellos que querían tocar compraban una guitarrita allí... una Gianinni ${ }^{32}$ [...] Gianinni era como si fuera una... Fender, ¿vale?, en la época. Compraba [...] una Tonante ${ }^{33}$ y un amplificadorFrahm; conectaba allí aquel timbre tenebroso del pedal EpiderSound ${ }^{34},[\ldots]$ aquel que solo hacía [...] más ruido [...] que efecto; y el equipo para presentaciones en vivo era el mismo equipo del

\footnotetext{
27 Es como se suele llamar en el sur de Brasil a los amplificadores de guitarra eléctrica, bajo, etc, .

28 Marca y modelo de un amplificador.

29 Está hablando de la ecualización de las frecuencias del instrumento.

30 En castellano sería Anarco-fiesta.

${ }^{31}$ Expresión que en el Sur de Brasil significa mucho ruido.

32 Marca de guitarras eléctricas.

33 Marca de guitarras.

${ }^{34}$ Marca del pedal de efectos.
} 
Autor/es, título, perifèria $x(y)$, mes 2016

revistes.uab.cat/periferia

garaje $^{35}$... Entonces, es decir: oías muy poco; oías más ruidêra... [...].Aquellos que conocían la banda [...] de los ensayos del garaje lograban identificar... [...]. Hoy en día no... Hoy en día la gente tiene más acceso a equipos [...] de punta y... a amplificadores mejores... Ves que la gente que va a tocar hoy [...] tiene amplificadores importados de calidad... En aquella época no: era paucomcorda ${ }^{36}$, como lo decíamos... Eran instrumentos muy precarios... Muy precarios... [...]. Entonces [...] era más ruido [...] que propiamente la música de la banda [...] (J.G.00:44':02').

Respecto a qué tipo de imagen sonora le viene a la cabeza cuando se acuerda de los festivales del underground pasado, hace un resumen de ese contexto a través de términos como ruido puro y noise para dibujar una representación del paisaje sonoro:

[...] [Entrevistador: ¿Esa es la imagen sonora que tienes...?] iLa imagen sonora que tengo..., hombre, de un festival como la Anarcofesta, es de que todo era ruido puro! iEra noise! iCualquier banda que fuera a presentarse podrías Ilamarla de noise rock! iPorque era muy noise así! Mal conseguías identificar la banda, el sonido... Raramente identificabas: 'iAh!, [...] ieso es un cover de Metallica!' [...] Y ahí el tío oía y decía: 'iVaya! iEso es!iEs Metallica! $[\ldots]^{\prime}[$ risas $][\ldots]$. Pero $[\ldots]$ el sonido era muy... la calidad sonora era muy

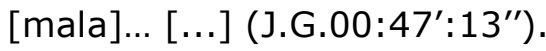

En la medida en que la música se distingue de los demás elementos de la cultura por tener como base el sonido, Ilama la atención la potencialidad memorial que emerge de los recuerdos de los festivales en lo que toca a la cuestión de las (re)construcciones de los paisajes sonoros pretéritos. Además, las percepciones mediadas por la distancia temporal entre pasado (lo vivido) y presente (el momento de la narrativa), hacen que surjan una serie de términos y expresiones émicas que buscan resumir-sintetizar imágenes del campo sonoro pasado. Tales

\footnotetext{
35 Es decir, el mismo equipo que las bandas utilizaban en sus ensayos.

36 Se trata de una expresión popular que se refiere a la mala calidad de un instrumento musical, equivalente en castellano a un palo con cuerda.
} 
Autor/es, título, perifèria $x(y)$, mes 2016

revistes.uab.cat/periferia

experiencias adjetivas narradas, traen metáforas que llevan por detrás el objetivo de dar sentido a un tipo de pintura del sonoro (Frith, 1998). El testimonio de G.T. cuando recuerda una presentación de su antigua banda en un festival que había sido realizado en un instituto de educación técnico-profesional, un evento en el que había contado con bandas y músicos del undergroundpelotense de esa época, (re)construye un escenario en el que el rasgo sonoro estaba marcado por la balbúrdia ${ }^{37}$ :

[...] nosotros tocamos allá y a mucha gente le ha gustado [...]. En el otro fin de semana, después del concierto, salimos y encontramos un montón de gente diciendo que había gustado mucho, que estaba muy guay y que aquello [que hemos tocado] era un jazz... iLa verdad es que aquello allí era unabalbúrdia! Porque yo estaba tocando al lado de la batería; yo escuchaba solo el sonido de la batería; no había monitores de escenario para la guitarra; el amplificador estaba orientado hacia delante [al público] y era un sitio largo, de manera que el sonido de la guitarra se iba todo para la platea y el sonido de la batería golpeaba en la pared del fondo y volvía con un retraso de... un gran delay... Era como: la batería a mí lado tocaba a tiempo y la que volvía tocaba a contratiempo. $\mathrm{Y}$ yo estaba en el medio de aquel fuego cruzado oyendo solo el sonido de la guitarra apagada. Solo aquel sonido de la guitarra [...] sin amplificar... Fue toda la presentación así [...] (G.T.01:39':54").

\section{Consideraciones finales}

Observamos a lo largo de este artículo que la temática del sonido se constituye como elemento significativo de lo que llamamos memoria de los paisajes sonoros. Los recuerdos del campo sonoro pretérito de parte de la cultura musical que estamos estudiando, remiten a representaciones que transponen un tipo de conocimiento acerca de sus experiencias sonoras pasadas al campo de una narrativa basada en el dibujar los sonidos pasados. Sin embargo, tal perspectiva no

\footnotetext{
${ }^{37}$ Alboroto, confusión, desorden.
} 
Autor/es, título, perifèria $x(y)$, mes 2016

revistes.uab.cat/periferia

queda solamente en el nivel de lo descriptivo. Va más allá. O sea: va a los sentidos memoriales en los que esas imágenes-recuerdos tienen una función.

Las (re)construcciones de las performances (el llevar cintas casete a bares y traileres) de ese tipo demusicar (Small, 1998) - el sonorizar pedazos frecuentados en la urbe pasada (Magnani, 2002) -, apuntan al sentido de la composición de paisajes sonoros rock armonizados con las prácticas sociales, así como con la constitución de territorios-espacios habitables que se identificaban con el género musical. Nos orientan a la noción de Small de que el propio significado no está en la música en sí misma sino en el musicar. Por tanto, el sonorizar los lugares frecuentados puede ser visto como una actividad-hábito pasado cuyo significado está en construir y mantener territorios habitables desde el sonoro hasta lo social. Lugares que, en el trabajo de la memoria, surgen como lugares memorables: memorables porque eran lugares en los que se podían conjugar actividades sociales como beber, conversar, estar con otras personas, etc, con los sonidos del rock.

Los recuerdos acerca de los paisajes sonoroscorrespondientes a los ensayos y festivales, no (re)construyen solamente imágenes de los rasgos sonoros sino también de sus condiciones de producción. Se tratan de memorias de las marcas históricas que caracterizan los paisajes sonoros (Woodside, 2008), una vez que se refieren a las condiciones de producción como marcas de una época a través de las cuales las percepciones de los entrevistados en el hoy, subrayan un sentido de la precariedad-dificultad. De esa forma, los propios rasgos del sonoro son vistos como también siendo sonidos precarios. Por tanto, queda claro que las memorias de los paisajes sonoros de la ERUP90son (re)construidas con base a la relación entre los propios referentes del entorno socio-musical (condiciones de producción sonora, obtención de equipos, etc) y los sonidos de ahí resultantes.

Por otro lado, las memorias de los paisajes sonorospresentadas no denotan solamente los sentidos de los sonidos en sí mismos. Las características del sonoro y de los entornos se enlazan - en términos de textura memorial -, a un contrapunto en el que se juega con el paso del tiempo. Como se ha visto a lo largo del texto, en algunos pasajes de las narrativas, el ayer y el hoy son puestos en comparación. Dicha performance memorial corresponde a lo que Candau $(2005 ; 2011)$ clasifica 
Autor/es, título, perifèria $x(y)$, mes 2016

revistes.uab.cat/periferia

como memoria generacional. Al mismo modo que Bennett (2013), cuando investiga acerca de cómo roqueros, punks, ravers, etc - alrededor de sus treinta-cuarentacincuenta años de edad (aging fans) - se relacionan con las escenas musicales actuales a las que acuden y de cómo se ven relacionándose con generaciones más jóvenes, dichas memorias manejan reflexiones semejantes. Es un tipo de performance memorial en la que el devenir emerge para significar el paso del tiempo a partir de las memorias de las prácticas musicales. Es lo que, así como Flores Mercado (2011), cuando tratando de las memorias musicales de músicos viejos de Totolapan (México), observa como alteridad:

[...] La descripción de las prácticas musicales del pasado permite aproximarnos a una identidad/alteridad, un nosotros -los músicos de antes- y un ellos -los músicos de ahora-. Dos identidades, dos formas de ser, hacer y pertenecer, dos habitus musicales diferenciados, ubicados en un mismo territorio pero en dos contextos temporales diferentes. Podemos decir que el tiempo vivido rige la interacción social entre el grupo de músicos de Totolapan; dimensión temporal que se expresa en la vida cotidiana en pares de categorías simbólicas: músico viejo y músico joven, músicos de los de antes y músicos de ahora [...] (Flores Mercado, 2011, p. 161).

De esa forma, las memorias de los paisajes sonoros de la ERUP90, como hemos presentado a lo largo de este artículo, se relacionan con una semántica memorial general que viene emergiendo en nuestro estudio. Del mismo modo que en otras categorías memoriales de esa memoria socio-musicalgeneral que estamos estudiando, hemos percibido que en varios puntos de las memorias de los paisajes sonoros hay una articulación entre épocas en la que emerge un contrapunto entre un nosotros -ayer - los que han tenido experiencias musicales percibidas como distintas de las de hoy-,que tiene un sentido cuando los colaboradores comparan las condiciones del mismo ayer con el hoy. El sentido de contraponer experiencias socio-musicales a partir de las condiciones de producción de sonido y de los paisajes sonoros correspondientes, demuestra una manera en la que la memoriaarticula una identidad basada en lo que llamamos alteridad temporal. Por tanto, muestran el carácter profundo y significativo de las prácticas socio-musicales 
Autor/es, título, perifèria $x(y)$, mes 2016

revistes.uab.cat/periferia

pretéritas en el terreno de la memoria. Además también muestran cómo la música, a través de lo que hemos llamado memorias socio-musicales, envuelve la indisolubilidad entre memoria e identidad (Candau, 2011; Pollak, 1992).

\section{Bibliografía}

Alberti, Verena (2000). Indivíduo e biografia na história oral. Centro de Pesquisa e Documentaçãode HistóriaContemporânea do Brasil CPDOC/FGV, 1-5.

Arroyo, Margarete (2010). Jovens, Músicas e percursos investigativos. ArtCultura, $12(20), 23-37$.

Atienza, Ricardo (2007). Ambientes sonoros urbanos: la identidad sonora. Modos de Permanencia y Variación de una configuración urbana.I Encuentro Iberoamericano sobre Paisajes Sonoros. Madrid: Auditorio Nacional.

Bennett, Andy (2004). Consolidating the music scenes perspective. Poetics, 32, 223-234.http://dx.doi.org/10.1016/j.poetic.2004.05.004

Bennett, Andy (2013). Music, style, and aging: growing old disgracefully?. Philadelphia: Temple University Press.

Candau, Jöel (2005). Antropologia da Memória. Lisboa: Instituto Piaget.

Candau, Jöel (2011). Memória e identidade. São Paulo: Contexto.

Denora, Tia (2000). Music in everyday life. Cambridge: Cambridge UniversityPress.

Ferreira, M. de M. \& Amado, J. (1998). Apresentação. En: Ferreira, M. de M. \& Amado, J. (Ed.).Usos e abusos da história oral (pp.v ii-xxv). Rio de Janeiro: Ed. FundaçãoGetúlio Vargas.

Frith, Simon (1998). Performing rites: on the value of popular music. Cambridge: Harvard UniversityPress.

Garzón, Adela (1993). Marcos sociales de la memoria: un enfoque ecológico. Psicothema, 5(1), 103-122.

Geertz, Clifford (2008). A interpretação das culturas. Rio de Janeiro: LTC. 
Autor/es, título, perifèria $x(y)$, mes 2016

revistes.uab.cat/periferia

Gomes, Rui Telmo (2012). Fazer música underground: estetização do cotidiano, circuitos juvenis e ritual. (Tesis inédita de doctorado). Instituto de CiênciasSociais da Universidade de Lisboa, Lisboa.

Halbwachs, Maurice (1990). A memóriacoletiva. São Paulo: EdiçõesVértice.

Halbwachs, Maurice (2004 [1925]). Los marcos sociales de la memoria. Barcelona: Anthropos Editorial.

Jovjelovitch, S. \& Bauer, M. (2008). Entrevista narrativa. En: Bauer, M. \&Gaskell, G. (Ed.). Pesquisa Qualitativacom Texto, Imagem e Som: um manual prático (pp. 90-113). Petrópolis: Vozes.

Magnani, José Guilherme Cantor (2002). De perto e de dentro: notas para umaetnografia urbana. Revista Brasileira de CiênciasSociais, 17(49), 1129.http://dx.doi.org/10.1590/S0102-69092002000200002.

Flores Mercado, B. Georgina (2011). Antes se tocaba papel, se estudiaba con un maestro: remembranzas de la educación musical rural en Totolapan, Morelos.Alteridades, 21(42), 149-163.

Misztal, Barbara A. (2003). Theories of social remembering. Philadelphia: Open University Press.

Oliveira Pinto, Tiago de (2001). Som e música. Questões de umaantropologia sonora. Revista de Antropologia, 44(1), 221286.https://dx.doi.org/10.1590/S0034-77012001000100007

Pollak, Michael (1992). Memória e Identidade Social. Estudos Históricos, 5(10), 200-215.

Portelli, Alessandro (2010). História Oral e Poder. Mnemosine, 6(2), 2-13.

Schafer, Raymond Murray (2011). A afinação do mundo: umaexploraçãopioneira pela históriapassada e pelo atual estado do maisnegligenciado aspecto do nosso ambiente: a paisagem sonora. São Paulo: Editora UNESP.

Silva, Sinésio J. Andrade (2014). Memória dos sons e sons da memória: umaetnografia musical da maré. Rio de Janeiro: Editora Multifoco. 
Autor/es, título, perifèria $x(y)$, mes 2016

revistes.uab.cat/periferia

Sinesio, J. Andrade (2009). Memória dos sons e os sons da memória: umaetnografia musical da Maré. (Tesis inédita de maestría). Escola de Música da Universidade Federal do Rio de Janeiro, Rio de Janeiro.

Small, Christopher (1998). Musicking: the meanings of performing and listening. Hanover: Wesleyan University Press.

Straw, Will (2004). Cultural scenes. Loisir et société/Society and Leisure, 27(2), 411-422.http://dx.doi.org/10.1080/07053436.2004.10707657

Woodside, Julian (2008). La historicidad del paisaje sonoro y la música popular. Trans. Revista Transcultural de Música (Sociedad de Etnomusicología), 12, 117. 